\title{
Pengembangan Sistem Informasi Pemesanan Layanan Jasa Cleaning Service Berbasis Web Dan Mobile Di Liochita Cleaning Semarang
}

\author{
Aulio Romadho Agung ${ }^{1)}$, Rinta Kridalukmana ${ }^{2)}$, Ike Pertiwi Windasari ${ }^{2)}$ \\ Program Studi Sistem Komputer, Fakultas Teknik, Universitas Diponegoro \\ Jalan Prof. Sudharto, Tembalang, Semarang, Indonesia
}

\begin{abstract}
Liochita cleaning is a company engaged in the field of cleaning services which are located in the city of Semarang. Until now, the existing of information systems on Liochita Cleaning were not sufficiently able to manage the company and thus to make this company as a company that developed and developing its field and can compete with other companies is not possible. Start from recording customer data and order data, which is the became one as income data, so this companies are less aware in detail of the customer data. On the other hand, customers must make a call in advance to order the services that it requires no small cost. Lack of marketing facilities makes this company unable to include all of costumers in the city of Semarang. Data recording is still using paper, so this company were at risk of paper lost which is containing data that has been recorded .

Development of an information system in this study using the method of the waterfall. Waterfall model consists of: requirements, design, implementation, testing and maintenance. For the start of the design, developer need to observations or interviews to determine the needs of the system that being developed. Applications developed using the framework CodeIgniter.

The results of this final project is an information system that can meet the needs of Liochita Cleaning in the management of these services, customers and orders in accordance with the business processes that Liochita Cleaning have and allow customers to book services.
\end{abstract}

Keywords: information systems, Android, CodeIgniter, Bootstrap

\section{PENDAHULUAN}

$\mathrm{L}$ iochita Cleaning merupakan perusahaan yang bergerak

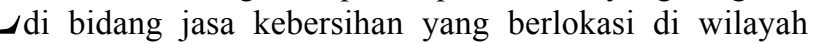
Semarang. Perusahaan ini melayani jasa pencucian karpet dan pembersihan kaca gedung.

Pada Liochita CLeaning pencatatan data pelanggan dan data pesanan yang masih menjadi satu yaitu data pemasukan sehingga perusahaan kurang mengetahui data pelanggan secara terperinci, serta pencatatan semua data yang ada masih menggunakan kertas hal ini memiliki resiko kertas dan data yang telah tercatat tersebut hilang.

Ilmu pengetahuan serta teknologi informasi saat ini telah mengalami perkembangan. Kemudahan dalam mengakses informasi yang dapat diakses dimanapun dan kapanpun inilah yang menjadikan pemanfaatan teknologi diterapkan hampir diberbagai bidang termasuk pada bidang wirausaha. Ketersediaan dan Kemudahan yang ditawarkan mampu menjaring lebih banyak konsumen bagi perusahaan yang bergerak di bidang usaha jasa kebersihan (cleaning service) serta memudahkan konsumen untuk melakukan pemesanan jasa, selain itu bagi perusahaan itu sendiri sistem informasi sangat membantu dalam penyimpanan dan pengolahan data yang masuk dan keluar serta mampu meningkatkan produktifitas perusahaan tersebut dan juga mampu meminimalisir terjadinya kehilangan data pada saat proses pengolahan data terjadi.

Sistem informasi dapat digunakan untuk membantu proses pemasaran dan pemesanan di Liochita Cleaning. Sebagai contoh, pemesanan jasa pencucian karpet atau pembersihan kaca gedung dapat dilakukan di dalam sebuah perangkat lunak serta pembuatan laporan transaksi juga dapat dilakukan berdasarkan data pemesanan.

Salah satu alternatif solusi dari permasalahan tersebut adalah sistem informasi berbasis web dan mobile yang diharapkan mampu memudahkan pelanggan dalam melakukan pemesanan, memudahkan karyawan untuk melakukan pelayanan dan pemasaran serta dapat digunakan untuk memonitor perusahaan bagi pemilik. Perangkat bergerak yang akan digunakan adalah jenis ponsel pintar dengan sistem operasi Android, maka sistem informasi berbasis mobile tersebut harus dirancang agar dapat dijalankan pada platform Android.

\section{LANDASAN TEORI}

$A$

\section{Penelitian Sebelumnya}

Sebelum melakukan pengembangan sistem diperlukan beberapa studi literatur untuk mengetahui efektivitas penggunaan sistem informasi pada pemesanan layanan.

Rakasiwi Syarief Hidayat ${ }^{[3]}$ berpendapat bahwa Sistem informasi pelayanan merupakan aplikasi komputer yang digunakan untuk bisnis yang berkaitan dengan jasa pelayanan, terutama dalam sistem penyimpanan dan pengolahan data maupun informasi agar dapat menjalani bisnis jasa dengan mudah dan berjalan dengan baik. Keadaan tersebut menyebabkan banyaknya perusahaan yang 
meningkatkan pengembangan di bidang pelayanan jasa untuk meningkatkan pelayanan yang lebih baik lagi.

Reza Milady Fauzan ${ }^{[2]}$ dari hasil penelitian yang dilakukan bahwa sistem informasi pemesanan produk berbasis web mampu meningkatkan kinerja perusahaan dengan semakin luasnya jangkauan pemasaran produk kepada konsumen, memudahkan konsumen untuk mendapatkan informasi secara lengkap dan cepat dan meminimalisir kesalahan data serta kesalahan perhitungan keuangan hasil transaksi terhadap konsumen.

Adriana Winina ${ }^{[8]}$ dalam penelitiannya berpendapat bahwa dengan pengelolaan pemesanan produk dan layanan jasa berbasis web dapat memudahkan admin dalam hal mencatat, menyimpan, dan menampilkan data untuk melakukan transaksi pemesanan produk maupun jasa. Menggunakan metode model-view-controller atau MVC mampu memisahkan pengembangan aplikasi berdasarkan komponen utama yang membangun sebuah aplikasi seperti manipulasi data, antarmuka pengguna, dan bagian yang menjadi kontrol dalam sebuah aplikasi web.

\section{$B \quad$ Sistem Informasi}

Sistem Sistem adalah sekumpulan unsur atau elemen yang saling berkaitan dan saling mempengaruhi dalam melakukan kegiatan bersama untuk mencapai tujuan bersama. Suatu sistem harus mempunyai sasaran, tujuan, komponen-komponen yang saling berinteraksi satu sama lainnya sehingga dapat mencapai tujuan yang telah ditetapkan. Informasi merupakan fakta yang memiliki arti sehingga memungkinkan untuk dimanfaatkan. Sedangkan semua fakta tersebut yang tercatat, terekam atau terdokumentasikan disebut data.

Burch dan Grudnitski [4] pada tahun 1989 berpendapat bahwa Informasi memiliki tingkat kualitas yang ditentukan. Informasi haruslah akurat yaitu informasi harus bebas dari kesalahan-kesalahan dan harus jelas penyampaian maksudnya. Informasi harus tepat waktu yaitu informasi yang dating tidak boleh terlambat kepada penerimanya. Informasi harus relevan yaitu informasi harus mempunyai manfaat bagi pengguna.

\section{Kerangka Kerja Codeigniter}

Codeigniter adalah aplikasi open source yang berupa framework untuk membangun website dinamis dengan menggunakan bahasa pemrograman PHP. Codeigniter menawarkan kemudahan serta standarisasi dalam proses pengembangan website dan aplikasi berbasis web. Dengan Codeigniter proses pengembangan website menjadi lebih cepat dan terstandar. Standar ini sangat berguna dalam pengembangan website yang dikerjakan oleh tim.

Laravel Codeigniter juga telah menyediakan library dan helper yang berguna dan mempermudah proses development. Terdapat beberapa kelebihan penggunaan Codeigniter dalam pengembangan suatu proyek, yaitu :

1. Menghemat Waktu

2. Code Reuse

3. Dukungan Komunitas

4. Kumpulan Best Practice

Codeigniter dibangun menggunakan konsep ModelView-Controller development pattern, yaitu sebuah teknik pemrograman yang memisahkan logika bisnis, logika data, dan logika presentasi ${ }^{[7]}$.

\section{Twitter Bootsrap}

Menurut Spurlock ${ }^{[6]}$ Twitter Bootstrap merupakan sebuah framework yang dikembangkan oleh Twitter guna menciptakan sebuah tampilan web yang responsif. Sejak peluncurannya pada tahun 2011 Twitter Bootstrap telah digunakan oleh banyak pengembang web karena kemampuannya untuk menyesuaikan bentuk dan ukuran tampilan aplikasi sesuai perangkat pengguna.

Twitter Bootstrap terdiri dari CSS, Javascript dan berkas gambar yang telah di gabungkan sehingga dapat digunakan oleh pengembang web. Untuk penggunaan Twitter Bootstrap dalam sebuah modul pengembangan web file CSS dan Javascript direferensikan di dalam file HTML

Penggunaan Twitter Bootstrap dapat mempermudah developer dalam mempercantik web yang dibuatnya dan mengurangi waktu pengerjaan dalam pembuatan sebuah website.

\section{E MySQL Server}

MySQL adalah salah satu jenis basis data server yang sangat terkenal dan banyak digunakan untuk membangun aplikasi web yang menggunakan basis data sebagai sumber dan pengelolaan datanya. Kepopuleran MySQL antara lain karena MySQL menggunakan SQL sebagai bahasa dasar untuk mengakses basis data-nya sehingga mudah untuk digunakan, kinerja query cepat, dan mencukupi untuk kebutuhan basis data perusahaanperusahaaan skala menengah-kecil. MySQLjuga bersifat open source dan gratis pada berbagai platform. MySQL didistribusikan dengan lisensi open source GPL (General Public License) mulai versi 3.23, pada bulan Juni $2000^{[1]}$.

Sistem basis data $M y S Q L$ didukung oleh bahasa operasional SQL. SQL singkatan dari Structured Query Language. SQL merupakan bahasa query standar yang digunakan untuk mengakses basis data relasional.

Kemampuan SQL tidak hanya untuk query (memperoleh data) saja, tetapi juga mencakup kemampuan lain, seperti pendefinisian struktur data, pengubahan data, pengaturan sekuritas, dan lain-lain. SQL belum dapat dikatakan sebagai bahasa tetapi sebagai subbahasa. Hal ini karena SQL tidak mendukung persyaratan bahasa yang lengkap seperti pernyataan penguji kondisi dan pengulangan atau iterasi. Sebagai server basis data, MySQL dapat dikatakan lebih unggul dibandingkan server basis data lainnya dalam query data ${ }^{[5]}$.

\section{PERANCANGAN SISTEM}

\section{A Analisis Kebutuhan}

Penyusunan analisis kebutuhan dilakukan untuk mengurangi risiko sistem gagal dikembangkan. Kegagalan pengembangan sistem umumnya terjadi karena sistem tidak memenuhi kebutuhan pengguna atau sistem tidak sesuai dengan proses bisnis yang berjalan. Studi kelayakan perlu dilakukan dalam penyusunan analisis kebutuhan untuk menghindari risiko tersebut. Studi kelayakan dapat dilakukan dengan cara wawancara, observasi dan membaca dokumen. Hasil analisis kebutuhan berupa dokumen System Requirements Specifications (SRS). Pengembangan ini menggunakan struktur SRS tersebut untuk menyampaikan analisis kebutuhan.

\section{1) Kondisi Awal}

Proses selama wawancara dan observasi memberikan gambaran kondisi yang terjadi dilapangan. Pada proses pemesanan, terdapat beberapa aktivitas yang harus dilakukan, antara lain:

1. Admin menerima pesanan yang masuk.

2. Admin memeriksa tanggal yang kosong untuk mengerjakan pesanan pelanggan agar pesanan yang masuk dapat segera diproses.

3. Admin memberikan konfirmasi kepada pelanggan yang memesan.

Jika ketiga proses tersebut telah dilalui, proses dapat berlanjut menuju persetujuan. Apabila persetujuan telah Jurnal Teknologi dan Sistem Komputer, Vol.4, No.1, Januari 2016 (e-ISSN: 2338-0403)

JTsiskom - 35 
dilakukan, aktivitas dalam proses tersebut akan bertambah menjadi:

1. Admin mengecek kembali pesanan dan informasi harga yang harus di bayar.

2. Admin mengubah status pesanan pelanggan.

3. Admin mencatat bahan baku yang digunakan untuk memenuhi kebutuhan pesanan pelanggan.

4. Admin memberi informasi kepada pelanggan bahwa pekerjaan telah selesai.

5. Admin mengubah status pembayaran dan menambahkan transaksi tersebut ke dalam laporan pendapatan.

6. Admin memberikan laporan pendapatan kepada pemilik.

Dari proses yang ada maka dapat dianalisis data yang diolah sebelum sistem dikembangkan. Data tersebut yaitu:
a. Nama pelanggan
b. Alamat pelanggan (untuk pengiriman)
c. Jenis jasa (cuci karpet atau cuci kaca gedung)
d. Harga layanan
e. Bahan baku
f. Detail pesanan

Pembuatan SRS dapat dilakukan setelah data yang dikumpulkan pada kondisi awal sudah cukup menjelaskan keadaan sebelum sistem dikembangkan.

2) Deskripsi Umum Sistem

Deskripsi umum sistem diperlukan untuk menjelaskan perspektif produk akhir hasil pengembangan, fungsi produk yang diharapkan untuk berjalan, kelompok pengguna, lingkungan pengoperasian serta lingkungan pengguna yang akan menggunakan sistem.

1. Perspektif Produk Akhir

Produk pengembangan adalah sistem informasi yang dapat digunakan oleh Liochita Cleaning dalam melakukan pelayanan. Sistem informasi tersebut digunakan untuk mengelola data aktivitas pemesanan jasa.

2. Fungsi Produk

Sistem informasi dapat menyimpan data pemesanan. Pengolahan transaksi dapat dilakukan lebih cepat menggunakan komputer. Data yang disimpan dalam sistem dapat diolah untuk menghasilkan laporan.

3. Kelompok Pengguna

Pengguna yang menggunakan sistem ini terdiri dari 3 jenis, yaitu: pengguna admin, pengguna pelanggan dan pengguna owner atau pemilik. ketiga pengguna tersebut memiliki aktivitas yang berbeda dalam menggunakan sistem.

a. Pengguna admin adalah pengguna yang bertugas melakukan pengelolaan terhadap pengguna pelanggan, data bahan baku dan data transaksi pemesanan. Pengguna admin berperan sebagai staf Liochita Cleaning.

b. Pengguna pelanggan adalah pengguna yang melakukan aktivitas pemesanan. Pengguna pelanggan merupakan pelanggan dari Liochita Cleaning yang akan melakukan pemesanan layanan jasa.

c. Pengguna owner adalah pengguna yang melakukan pengelolaan terhadap pengguna admin dan memonitor data transaksi pemesanan.

4. Lingkungan Pengoperasian

Sistem dioperasikan di Liochita Cleaning. Liochita Cleaning menggunakan koneksi internet dalam mengoperasikan sistem. SIstem bisa digunakan sepanjang hari selama server dan jaringan tidak mengalami gangguan.

5. Lingkungan Pengguna

Pada sisi Butik Goddies Fashion aplikasi berupa aplikasi berbasis web. Pengguna bisa mengakses sistem melalui web browser dari perangkat komputer atau tablet, sedangkan pada sisi pelanggan Butik Goddies Fashion aplikasi berupa aplikasi ponsel pintar yang telah dipasang sebelumnya.

3) Kebutuhan Fungsional

Sistem yang dikembangkan diharapkan dapat memenuhi kebutuhan fungsional agar dapat digunakan sesuai dengan proses bisnis yang telah berjalan pada sisi admin Liochita Cleaning. Berikut adalah kebutuhan fungsional yang harus dipenuhi oleh sistem.

1. Admin dapat menyimpan, mengubah dan menghapus data pelanggan. Fungsi tersebut bertujuan untuk memastikan bahwa pelanggan yang terdaftar benarbenar pelanggan yang ingin menggunakan jasa Liochita Cleaning.

2. Fitur order yang digunakan untuk menambah, mengubah, membatalkan dan menghapus pesanan yang masuk hanya dapat dikelola oleh Admin.

3. Fitur bahan baku digunakan untuk mengelola bahan baku yang keluar saat memenuhi pengerjaan pesanan dan dan digunakan untuk pembelian bahan baku apabila stok bahan baku kurang.

4. Fitur keuangan digunakan oleh Admin dan Pemilik untuk melihat laporan pemasukan dan laporan pengeluaran secara periodik maupun tahunan.

5. Fitur kelola data digunakan untuk mengelola data wilayah kecamatan dan ongkos kirim yang berisi tarif harga yang dikenakan pelanggan saat melakukan pemesanan berdasarkan kecamatan tempat tinggal pelanggan, data supplier dan nonsupplier berisi rekanan perusahaan yang digunakan untuk memenuhi kebutuhan bahan baku Liochita Cleaning, data produk yang berisi jasa yang ditawarkan Liochita Cleaning.

6. Pemilik dapat menambahkan, menyimpan, mengubah dan menghapus data admin. Fungsi tersebut bertujuan agar Admin yang tidak lagi bekerja pada Liochita Cleaning tidak bisa mengakses kedalam sistem.

7. Pelanggan dapat menambahkan pesanan layanan berupa jasa cuci karpet atau cuci kaca gedung setelah melakukan pendaftaran kedalam sistem.

8. Fitur profil saya digunakan Pelanggan untuk mengelola informasi profil tentang data diri Pelanggan dan mengelola akun yang digunakan Pelanggan untuk masuk kedalam sistem.

9. Fitur order terakhir digunakan Pelanggan untuk melihat status pesanan yang telah di pesan.

10. Fitur histori pesanan digunakan Pelanggan untuk melihat pesanan yang pernah dilakukan oleh Pelanggan.

11. Sistem memiliki fasilitas untuk Pelanggan guna melihat daftar dan detail jasa yang ditawarkan oleh Liochita Cleaning.

4) Kebutuhan Non-Fungsional

Selain kebutuhan fungsional sistem juga harus memenuhi kebutuhan non-fungsional agar sistem yang berjalan dapat digunakan dengan baik oleh pengguna pada sisi admin Liochita Cleaning maupun sisi pelanggan Liochita Cleaning. Berikut merupakan kebutuhan fungsional yang harus dipenuhi oleh sistem. 
1. Operasional

a. Sistem yang bekerja pada admin dan owner Liochita Cleaning dapat diakses dari perangkat komputer dan tablet.

b. Sistem memiliki fitur pemberitahuan pesan kesalahan muncul jika pengguna melakukan kesalahan pemakaian sistem.

c. Sistem dapat memperbarui data secara otomatis.

2. Keamanan

a. Sistem memiliki fungsi login untuk memberikan akses ke pengguna.

b. Sistem memiliki fungsi role untuk membedakan hak pengguna.

c. Sistem mengimplementasikan metode soft delete untuk menjaga validasi pengolahan data

SRS yang dihasilkan dari analisis kebutuhan digunakan sebagai bahan perancangan sistem. Kebutuhan fungsional di dalam SRS menentukan bagaimana sistem harus dibangun sehingga mampu memenuhi kebutuhan yang diharapkan. Spesifikasi teknis dibuat pertama kali dalam perancangan untuk menetapkan lingkungan pengembangan. Pemodelan dilakukan setelah spesifikasi sistem selesai ditentukan. Penulisan kode belum bisa dimulai sebelum pemodelan selesai dibuat. Penulisan kode tanpa memperhatikan pemodelan akan menimbulkan risiko kegagalan pengembangan. Desain antarmuka dilakukan setelah pemodelan selesai dibuat sehingga sistem mampu dioperasikan pengguna dengan mudah. Pengembangan aplikasi yang mengabaikan desain antarmuka user friendly cenderung susah digunakan.

\section{1) Spesifikasi Teknis}

1. Arsitektur Sistem

Sistem yang dikembangkan berupa aplikasi berbasis web dan aplikasi mobile. Web server dibutuhkan untuk menjalankan aplikasi tersebut. Data yang diolah sistem disimpan pada basis data. Server basis data juga dibutuhkan untuk menjalankan basis data yang digunakan sistem. Pengguna dapat mengakses sistem melalui web browser dengan cara memanggil URL aplikasi.

2. Arsitektur Aplikasi

Deskripsi umum SRS menjelaskan bahwa sistem berupa aplikasi web pada sisi admin Liochita Cleaning dan aplikasi perangkat bergerak serta aplikasi web pada pelanggan Liochita Cleaning. Bahasa yang dipakai adalah PHP dengan kerangka kerja Coderigniter 3.0.

3. Kebutuhan Perangkat Keras

Kebutuhan perangkat keras bagi pengguna sistem ini memerlukan PC yang dapat menjalankan web browser, dari berbagai macam kebutuhan minimal web browser, maka perangkat keras yang dibutuhkan pada sisi pengguna adalah sebagai berikut:

- Prosesor: Intel Pentium 4

- $\quad$ RAM : $512 \mathrm{MB}$

- HDD : 4 GB

Untuk sistem yang berjalan pada perangkat bergerak bagi pengguna pelanggan Liochita Cleaning memerlukan perangkat bergerak dengan spesifikasi minimal RAM 512 MB.

4. Kebutuhan Perangkat Lunak

Kebutuhan perangkat lunak merupakan kebutuhan yang diperlukan untuk mendukung implementasi sistem yang dibangun. Kebutuhan aplikasi dibagi menjadi tiga kategori, yaitu :

\section{Operasional}

Kebutuhan minimum yang diperlukan untuk menjalankan sistem informasi yang akan dibangun ini adalah sebagai berikut :

\section{a. Sistem Operasi}

Sistem operasi yang dapat digunakan untuk menjalankan aplikasi ini antara lain Windows, Mac OS,Linux dan dibutuhkan sistem operasi Android versi 4.1 bagi pengguna di sisi Pelanggan.

b. PHP (PHP : Hypertext Preprocessor)

Spesifikasi versi PHP minimum yang dapat digunakan yaitu versi 5.1.6.

\section{c. Web Browser}

Untuk dapat menjalankan sistem informasi yang akan dibangun, dibutuhkan web browser pada sisi Admin maupun Pelanggan. Web Browser yang dapat digunakan antara lain Internet Explorer versi 7+, Mozilla Firefox, Google Chrome, Safari, dan Opera.

d. Basis Data

Basis data yang digunakan untuk menyimpan data menggunakan MySQL 4.1+.

\section{Antarmuka}

Antarmuka merupakan tampilan yang disajikan dari aplikasi yang dibuat. Antarmuka menentukan bagaimana pengguna dapat memahami dan menggunakan sebuah aplikasi. Antarmuka yang baik adalah antarmuka yang mampu memberikan tujuan dengan baik kepada pengguna, dan pewarnaan serta tatanan layout membuat pengguna nyaman dalam menggunakan aplikasi. Pada antarmuka aplikasi ini menggunakan kerangka kerja Twitter Bootstrap.

3. Keamanan

Keamanan data merupakan salah satu unsur penting dalam pembuatan sebuah sistem terutama dalam menjaga data dari pengguna yang tidak berwenang untuk mengolah data tersebut. Dalam sistem ini, pengamanan dilakukan dengan mengenkripsi password pengguna dengan menggunakan metode MD5..

\section{2) Desain ERD}

Sistem yang dikembangkan merupakan sistem yang berfungsi untuk mengolah data. Pemodelan perlu dilakukan untuk menentukan data yang diolah. Pemodelan tersebut dilakukan setelah spesifikasi teknis ditentukan. ERD digunakan untuk memodelkan data yang akan disimpan dalam basis data. Langkah yang dilakukan dalam merancang ERD adalah menentukan entitas yang ada, lalu entitas tersebut dihubungkan dalam notasi diagram.

1. Menentukan Entitas

Entitas dapat ditentukan dari SRS. Kebutuhan yang dijelaskan memberikan gambaran data-data yang diolah. Data tersebut merupakan entitas yang akan digunakan dalam merancang ERD. Tabel 1 menunjukkan entitas yang telah ditentukan.

Tabel 1 Tabel Entitas ERD

\begin{tabular}{|l|l|l|}
\hline No & Nama & Keterangan \\
\hline 1. & belibahanbaku & Data pembelian bahan baku \\
\hline 2. & karpet & Data tarif karpet \\
\hline 3. & data_penjual & Data keseluruhan penjual \\
\hline 4. & jenis_karpet & Data jenis-jenis karpet \\
\hline 5. & gedung & Data tarif gedung \\
\hline 6. & nama_bahan & Data nama-nama bahan baku \\
\hline 7. & order_gedung & Data pesanan gedung \\
\hline 8. & order_karpet & Data pesanan karpet \\
\hline 9. & pengguna & Data pengguna \\
\hline 10. & stok digunakan & Data stok bahan baku yang \\
\hline
\end{tabular}




\begin{tabular}{|l|l|l|}
\hline & & digunakan \\
\hline 11. & stok_bahanbaku & $\begin{array}{l}\text { Data stok bahan baku yang } \\
\text { tersisa }\end{array}$ \\
\hline 12. & penjual & Data nama penjual \\
\hline 13. & user_credential & Data akun pengguna \\
\hline 14. & $\begin{array}{l}\text { ongkos_by_wilaya } \\
\text { h }\end{array}$ & $\begin{array}{l}\text { Data wilayah kecamatan di } \\
\text { kota semarang dan ongkos } \\
\text { kirim }\end{array}$ \\
\hline
\end{tabular}

2. Menggambar Diagram

Diagram dapat digambarkan setelah seluruh entitas didefinisikan beserta atributnya. Tujuan dari diagram adalah menjelaskan hubungan antara entitas yang telah ditentukan. Relasi yang digambarkan dapat diperjelas dengan menambahkan informasi kardinalitas antara entitas.

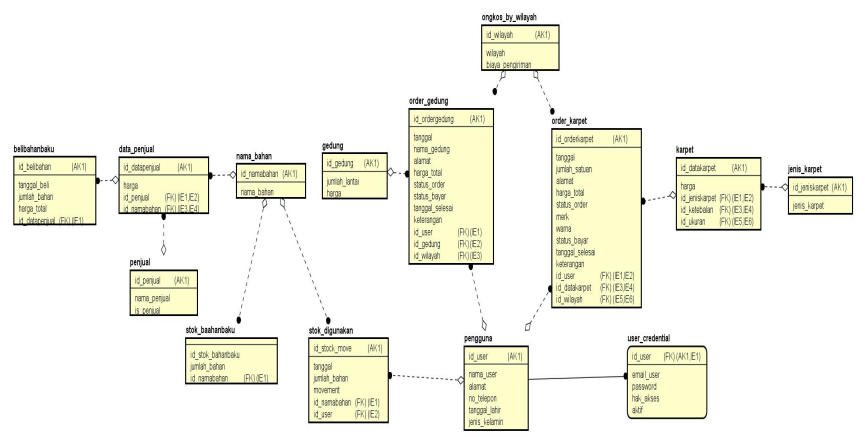

Gambar 1 Diagram ERD Keseluruhan Sistem

Diagram yang menggambarkan keseluruhan sistem tersebut dapat menjelaskan semua data yang diolah sistem. Gambar 1 Menunjukkan ERD keseluruhan sistem.

3) Desain UML

Fungsi yang ditunjukkan pada SRS belum memiliki detail yang cukup untuk dikembangkan. Pemodelan UML memberikan ruang untuk mengembangkan detail fungsi yang dibutuhkan oleh sistem sebelum penulisan kode dimulai. Kesalahan yang dilakukan pada pemodelan akan lebih mudah dianalisis dan diperbaiki daripada saat sistem sudah ditulis dengan bahasa pemrograman.

1. Diagram Aktivitas Sistem

Diagram aktivitas dibuat pada awal pemodelan UML untuk memberikan perspektif mengenai proses bisnis yang dilakukan.

Gambar 2 menunjukkan diagram aktivitas sistem yang dikembangkan. Proses bisnis sistem ini dimulai ketika pelanggan melihat produk layanan jasa dan berakhir hingga admin mengubah status pembayaran.

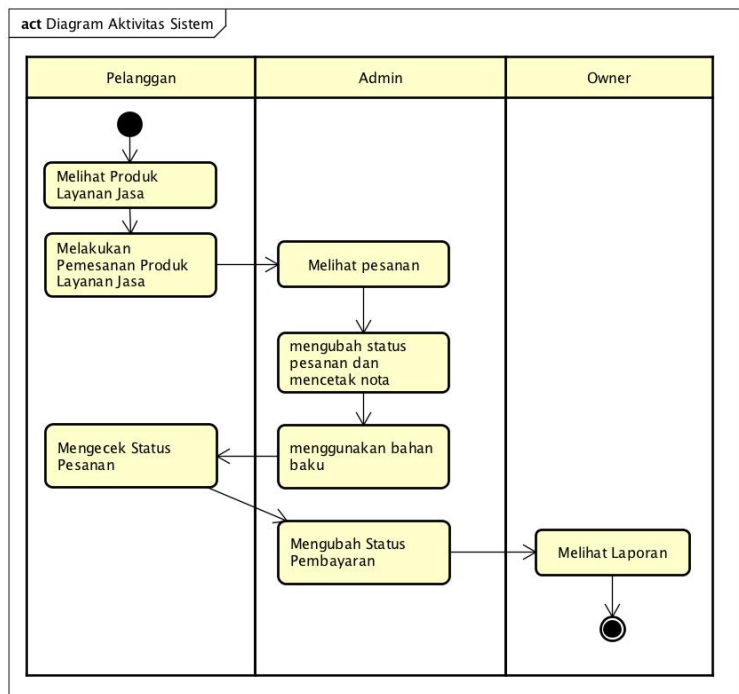

Gambar 2 Diagram Aktivitas Sistem

Jurnal Teknologi dan Sistem Komputer, Vol.4, No.1, Januari 2016 (e-ISSN: 2338-0403)
2. Diagram Use Case Sistem

Bagaimana pengguna menggunakan sistem dapat digambarkan dengan diagram use case. Diagram use case dibuat berdasarkan skenario yang dilakukan pengguna ketika menggunakan fungsi sistem. Diagram use case terlihat pada Gambar 3.

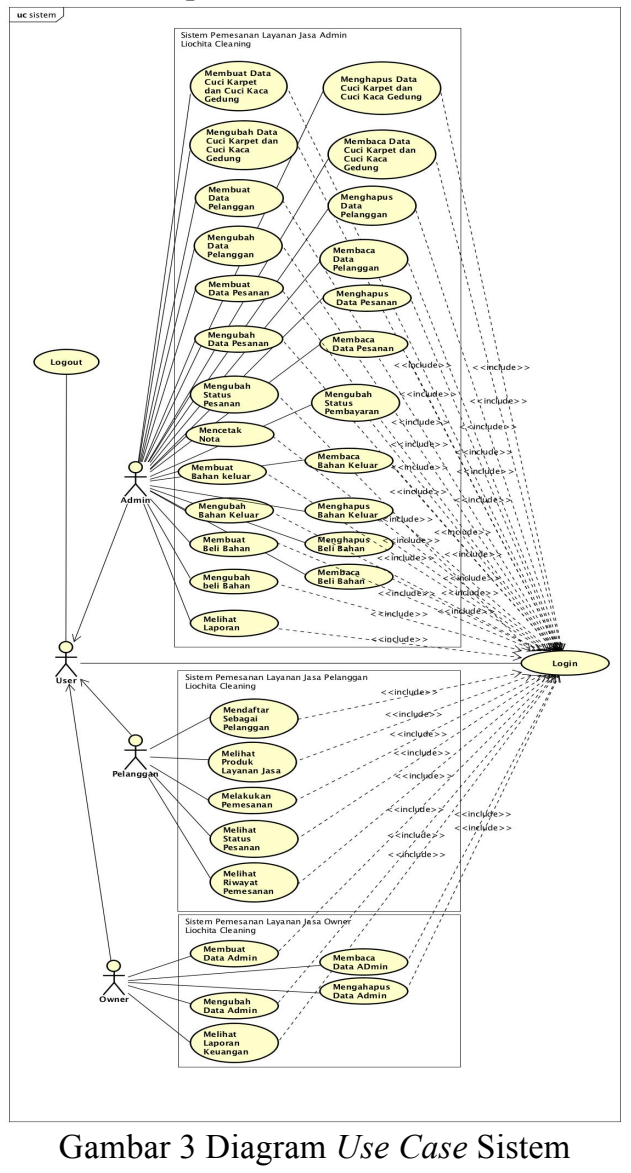

Pemodelan diagram use case menunjukkan bahwa sistem terdapat 3 aktor yang menggunakan sistem. Sistem memiliki tiga puluh lima skenario umum.

3. Diagram kelas

Diagram kelas pada gambar 4 menunjukkan kelas dengan atribut yang saling terhubung dengan kelas lain.

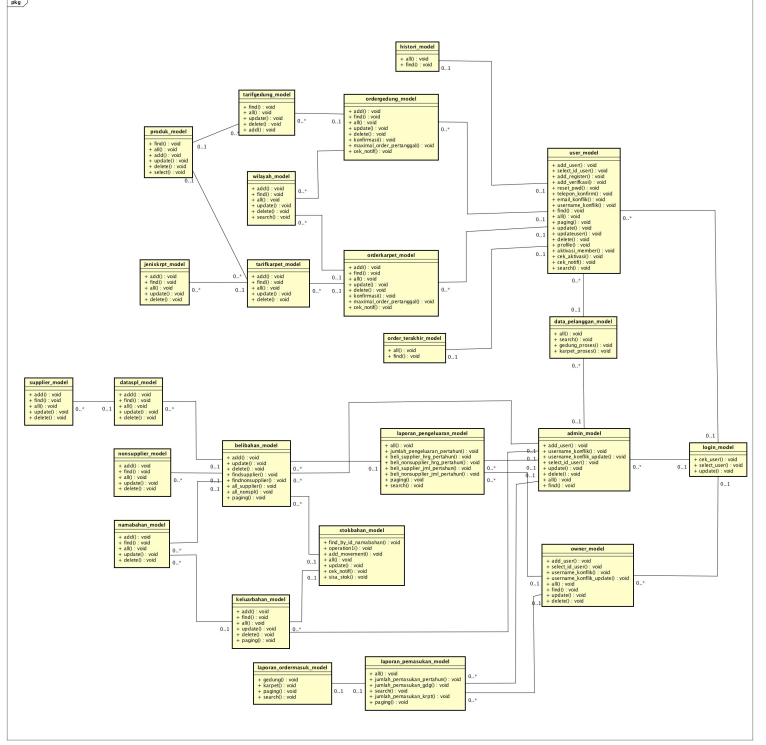

Gambar 4 Diagram kelas tipe model keseluruhan sistem

Kelas yang ada pada Gambar 3.48 tersebut merupakan kelas dengan tipe model yang berfungsi sebagai abstraksi basis data. Semua model yang ada merupakan

\begin{tabular}{l} 
2338-0403) JTsiskom - 38 \\
\hline
\end{tabular} 
extend dari kelas active record yang berfungsi sebagai penghubung dengan kelas tipe controller.

Diagram kelas pada gambar 5 menunjukkan kelas controller yang berfungsi sebagai pengolah Business logic.

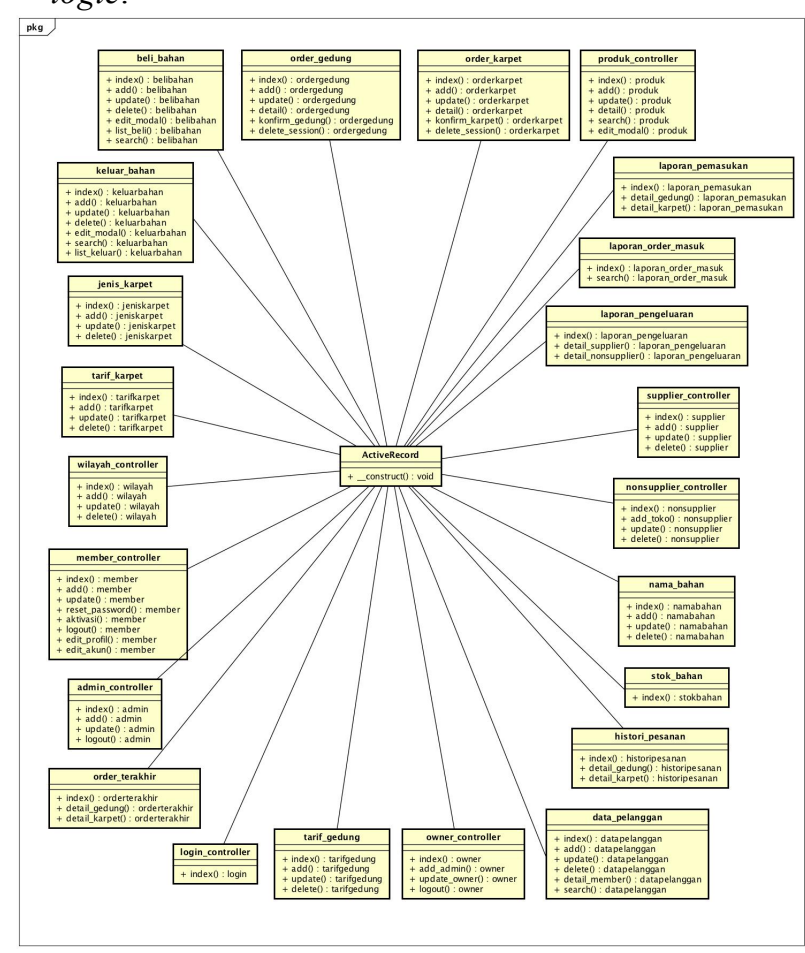

Gambar 5 Diagram kelas tipe controller keseluruhan sistem

Kelas controller dapat berinteraksi dengan data di dalam basis data dengan Active Record. Deskripsi masing - masing kelas ditunjukkan pada tabel 2.

Tabel 2 Deskripsi diagram kelas

\begin{tabular}{|l|l|l|}
\hline $\begin{array}{l}\text { N } \\
\mathbf{o}\end{array}$ & Kelas & Deskripsi \\
\hline 1 & supplier_model & Model data supplier \\
\hline 2 & nonsupplier_model & Model data non supplier \\
\hline 3 & keluarbahan_model & $\begin{array}{l}\text { Model data bahan baku } \\
\text { digunakan }\end{array}$ \\
\hline 4 & namabahan_model & Model data nama bahan \\
\hline 5 & belibahan_model & $\begin{array}{l}\text { Model data pembelian bahan } \\
\text { baku }\end{array}$ \\
\hline 6 & dataspl_model & $\begin{array}{l}\text { Model data keseluruhan } \\
\text { supplier }\end{array}$ \\
\hline 7 & $\begin{array}{l}\text { laporan_pengeluaran_- } \\
\text { model }\end{array}$ & $\begin{array}{l}\text { Model data } \\
\text { pengeluaran }\end{array}$ \\
\hline 8 & $\begin{array}{l}\text { laporan_ordermasuk_- } \\
\text { model }\end{array}$ & $\begin{array}{l}\text { Model data pesanan yang } \\
\text { masuk }\end{array}$ \\
\hline 9 & $\begin{array}{l}\text { laporan_pemasukan_ } \\
\text { model }\end{array}$ & $\begin{array}{l}\text { Model data } \\
\text { pemasukan }\end{array}$ \\
\hline 10 & stokbahan_model & Model data stok bahan \\
\hline 11 & owner_model & Model data pengguna owner \\
\hline 12 & admin_model & Model data pengguna admin \\
\hline 13 & login_model & Model data login pengguna \\
\hline 14 & jeniskrpt_model & Model data jenis karpet \\
\hline 15 & tarifkarpet_model & $\begin{array}{l}\text { Model data jenis dan tarif } \\
\text { cuci karpet }\end{array}$ \\
\hline 16 & orderkarpet_model & $\begin{array}{l}\text { Model data pesanan cuci } \\
\text { karpet }\end{array}$ \\
\hline 17 & order_terakhir_model & $\begin{array}{l}\text { Model data proses pesanan } \\
\text { pengguna pelanggan }\end{array}$ \\
\hline 18 & ordergedung_model & $\begin{array}{l}\text { Model data pesanan cuci } \\
\text { kaca gedung }\end{array}$ \\
\hline
\end{tabular}

\begin{tabular}{|c|c|c|}
\hline 19 & user_model & $\begin{array}{l}\text { Model data pengguna } \\
\text { pelanggan }\end{array}$ \\
\hline 20 & wilayah_model & $\begin{array}{lr}\text { Model data } & \text { biaya } \\
\text { pengiriman berdasar wilayah } \\
\text { kecamatan } & \text { pengguna } \\
\text { pelanggan } & \end{array}$ \\
\hline 21 & tarifgedung_model & $\begin{array}{l}\text { Model data jenis dan tarif } \\
\text { cuci kaca gedung }\end{array}$ \\
\hline 22 & produk_model & $\begin{array}{l}\text { model data cuci karpet dan } \\
\text { cuci kaca gedung }\end{array}$ \\
\hline 23 & $\begin{array}{l}\text { data_pelanggan_mode } \\
1\end{array}$ & $\begin{array}{l}\text { Model data keseluruhan } \\
\text { pelanggan }\end{array}$ \\
\hline 24 & histori_model & $\begin{array}{l}\text { Model data histori pesanan } \\
\text { pelanggan }\end{array}$ \\
\hline 25 & supplier_controller & $\begin{array}{l}\text { Controller yang mengelola } \\
\text { data supplier }\end{array}$ \\
\hline 26 & nonsupplier_controller & $\begin{array}{l}\text { Controller yang mengelola } \\
\text { data nonsupplier }\end{array}$ \\
\hline 27 & keluar_bahan & $\begin{array}{l}\text { Controller yang mengelola } \\
\text { data bahan baku digunakan }\end{array}$ \\
\hline 28 & nama_bahan & $\begin{array}{l}\text { Controller yang mengelola } \\
\text { data bahan baku }\end{array}$ \\
\hline 29 & beli_bahan & $\begin{array}{l}\text { Controller yang mengelola } \\
\text { data pembelian bahan baku }\end{array}$ \\
\hline 30 & laporan_order_masuk & $\begin{array}{l}\text { Controller yang mengelola } \\
\text { data laporan pesanan masuk }\end{array}$ \\
\hline 31 & laporan_pengeluaran & $\begin{array}{l}\text { Controller yang mengelola } \\
\text { data laporan pengeluaran }\end{array}$ \\
\hline 32 & laporan_pemasukan & $\begin{array}{l}\text { Controller yang mengelola } \\
\text { data laporan pemasukan }\end{array}$ \\
\hline 33 & stok_bahan & $\begin{array}{l}\text { Controller yang mengelola } \\
\text { data stok bahan baku }\end{array}$ \\
\hline 34 & data_pelanggan & $\begin{array}{l}\text { Controller yang mengelola } \\
\text { data keseluruhan pelanggan }\end{array}$ \\
\hline 35 & owner_controller & $\begin{array}{l}\text { Controller yang mengelola } \\
\text { data owner }\end{array}$ \\
\hline 36 & admin_controller & $\begin{array}{l}\text { Controller yang mengelola } \\
\text { data admin }\end{array}$ \\
\hline 37 & login_controller & $\begin{array}{l}\text { Controller yang mengelola } \\
\text { data login }\end{array}$ \\
\hline 38 & jenis_karpet & $\begin{array}{l}\text { Controller yang mengelola } \\
\text { data jenis karpet }\end{array}$ \\
\hline 39 & tarif_karpet & $\begin{array}{l}\text { Controller yang mengelola } \\
\text { data tarif cuci karpet }\end{array}$ \\
\hline 40 & order_karpet & $\begin{array}{l}\text { Controller yang mengelola } \\
\text { data pesanan cuci karpet }\end{array}$ \\
\hline 41 & order_gedung & $\begin{array}{l}\text { Controller yang mengelola } \\
\text { data pesanan cuci kaca } \\
\text { gedung }\end{array}$ \\
\hline 42 & order_terakhir & $\begin{array}{l}\text { Controller yang mengelola } \\
\text { data proses pesanan } \\
\text { pelanggan }\end{array}$ \\
\hline 43 & member_controller & $\begin{array}{l}\text { Controller yang mengelola } \\
\text { data pelanngan }\end{array}$ \\
\hline 44 & wilayah_controller & $\begin{array}{l}\text { Controller yang mengelola } \\
\text { data biaya pengiriman } \\
\text { berdasar wilayah kecamatan }\end{array}$ \\
\hline 45 & tarif_gedung & $\begin{array}{l}\text { Controller yang mengelola } \\
\text { data tarif cuci kaca gedung }\end{array}$ \\
\hline 46 & produk_controller & $\begin{array}{l}\text { Controller yang mengelola } \\
\text { data cuci karpet dan cuci } \\
\text { kaca gedung }\end{array}$ \\
\hline 47 & histori_pesanan & $\begin{array}{l}\text { Controller yang mengelola } \\
\text { data riwayat pemesanan } \\
\text { pelanggan }\end{array}$ \\
\hline
\end{tabular}

JTsiskom - 39 


\begin{tabular}{|l|l|l|}
\hline 48 & ActiveRecord & $\begin{array}{l}\text { Kelas yang digunakan oleh } \\
\text { controller untuk mengakses } \\
\text { model }\end{array}$ \\
\hline
\end{tabular}

Pemodelan yang dibuat sudah cukup untuk digunakan menjelaskan bagaimana sistem akan memenuhi kebutuhan sistem. Diagram aktivitas memberikan gambaran utama bagaimana sistem akan digunakan dalam proses bisnis. Diagram use case memberikan informasi bagaimana pengguna menggunakan sistem. Diagram sequence menampilkan perilaku sistem ketika digunakan pengguna. Diagram kelas menunjukkan struktur sistem.

Kode yang digunakan untuk membangun aplikasi bisa dikerjakan setelah tahap ini. Spesifikasi teknis dan pemodelan dapat memberikan gambaran dan arahan bagaimana kode ditulis. Penulisan kode kemudian dikerjakan hingga selesai.

\section{PENGUJian Sistem}

Pengujian integrasi dilakukan untuk mengetahui apakah setiap fungsi yang dimiliki sistem mampu saling terhubung untuk melakukan pekerjaan utama. Pengujian dilakukan karena kesalahan dalam sistem mungkin terjadi walaupun masing - masing fungsi telah diuji. Kesalahan seperti itu umumnya terjadi karena fungsi yang ada tidak terhubung atau tidak memiliki batasan yang sama dengan fungsi lainnya. Pengguna mengeksekusi banyak fungsi dalam melakukan pekerjaannya. Hubungan antar fungsi tersebut adalah bentuk integrasi unit. Skenario buatan atau simulasi pekerjaan dilakukan untuk menjalankan pengujian integrasi. Skernario yang dilakukan pada pengujian ini adalah sebagai

1. Liochita Cleaning memiliki beberapa data cuci karpet dan cuci kaca gedung

Admin Liochita Cleaning membuat data cuci karpet dengan jenis karpet permadani, ketebalan karpet tipis dan ukuran karpet kecil, serta membuat data cuci kaca gedung dengan jumlah lantai 3. Tampilan pembuatan data cuci karpet ditunjukkan pada Gambar 6 dan tampilan untuk pembuatan data cuci karpet ditunjukkan pada Gambar 7 .

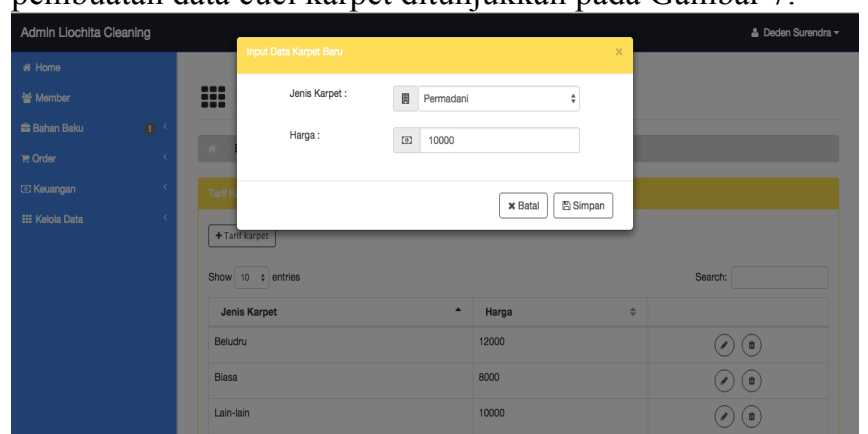

Gambar 6 Pengujian integrasi membuat data cuci karpet

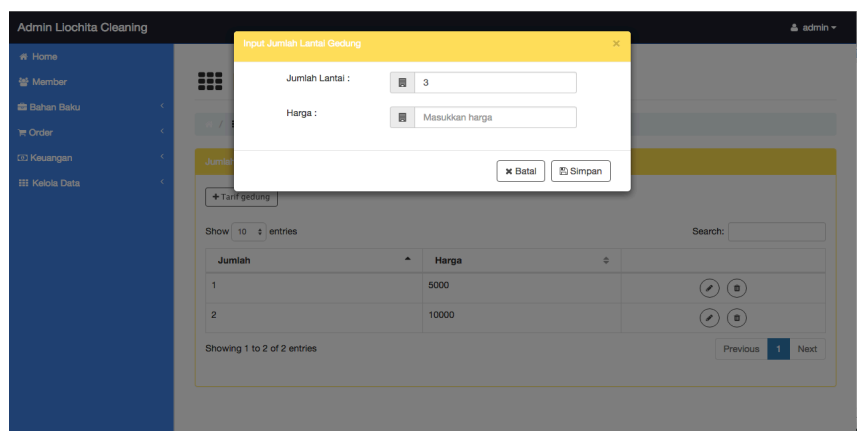

Gambar 7 Pengujian integrasi membuat data cuci kaca gedung
Data cuci karpet dan cuci kaca gedung yang dibuat oleh Admin Liochita Cleaning akan ditampilkan kepada pelanggan saat akan melukan pemesanan.

\section{Pelanggan mendaftar}

Pelanggan harus melakukan pendaftaran terlebih dahulu untuk melakukan kegiatan pemesanan layanan jasa, melihat status pesanan, melihat riwayat pemesanan Pada pengujian ini pelanggan dengan nama Aulio Romadho Agung melakukan pendaftaran menggunakan email aulioromadho@gmail.com email ini digunakan untuk melakukan aktivitas login. Gambar 8 menunjukkan proses pendaftaran pelanggan.

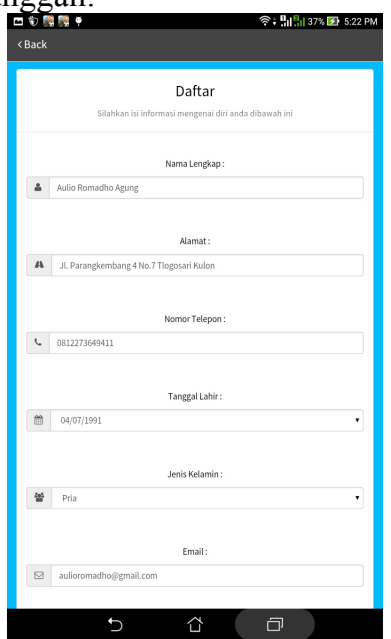

Gambar 8 Pengujian integrasi mendaftar sebagai pelanggan

Pelanggan yang mendaftar pertama kali diharuskan mengaktifkan akun melalui email yang telah didaftarkan kedalam sistem, sistem akan mengirim pesan kepada pelanggan melalui email yang berisi link aktivasi.

3. Pelanggan melakukan pemesanan layanan jasa

Akun yang telah diaktifkan oleh pelanggan dapat digunakan untuk melakukan kegiatan login untuk bisa mengakses fiturpemesanan layanan jasa, melihat status pesanan, melihat riwayat pemesanan. Gambar 9 menunjukkan proses login oleh pelanggan.

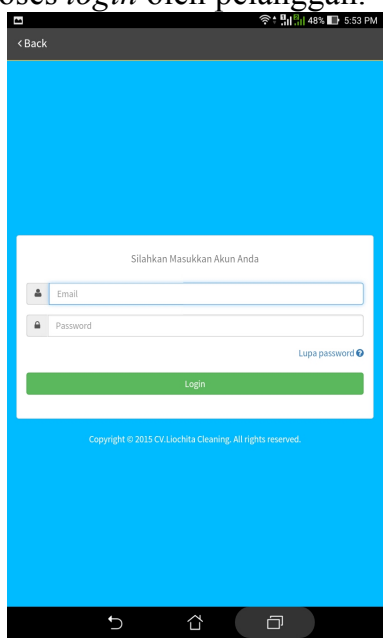

Gambar 9 Pengujian integrasi aktivitas login

Email aulioromadho@gmail.com digunakan untuk melakukan login. Untuk melakukan kegiatan pemesanan layanan jasa, pelanggan mengisi form data pesanan sesuai jasa yang akan digunakan. Gambar 10 menunjukkan pemesanan layanan jasa cuci kaca karpet dan Gambar 11 menunjukkan pemesanan layanan jasa cuci kaca gedung 


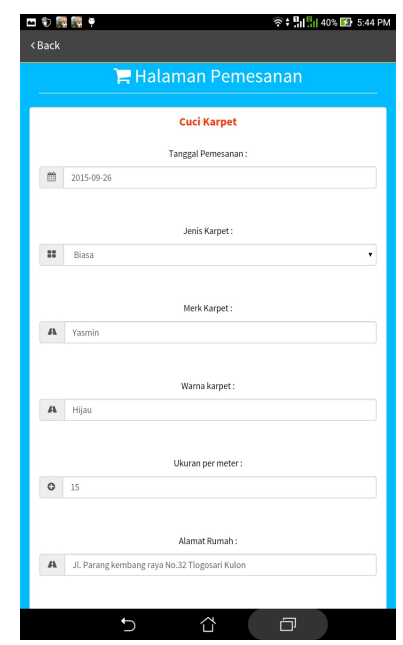

Gambar 10 Pengujian integrasi melakukan pemeseanan jasa cuci karpet

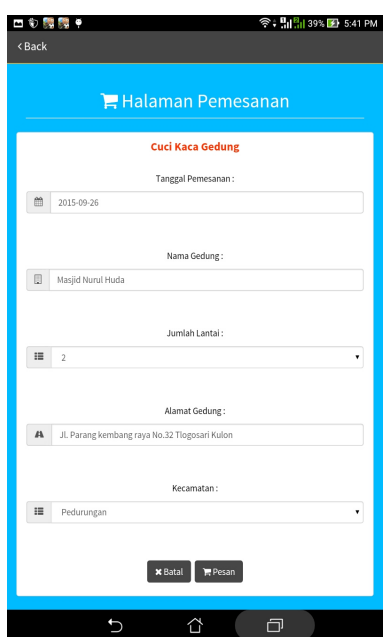

Gambar 11 Pengujian integrasi melakukan pemesanan jasa cuci kaca gedung

4. Admin mengelola pesanan yang telah dilakukan oleh pelanggan

Kegiatan Pemesanan yang dilakukan pelanggan akan dilihat oleh admin terlebih dahulu. Gambar 12 menunjukkan pemesanan jasa cuci karpet dan Gambar 13 menunjukkan pemesanan jasa cuci kaca gedung dengan nama Aulio Romadho Agung.

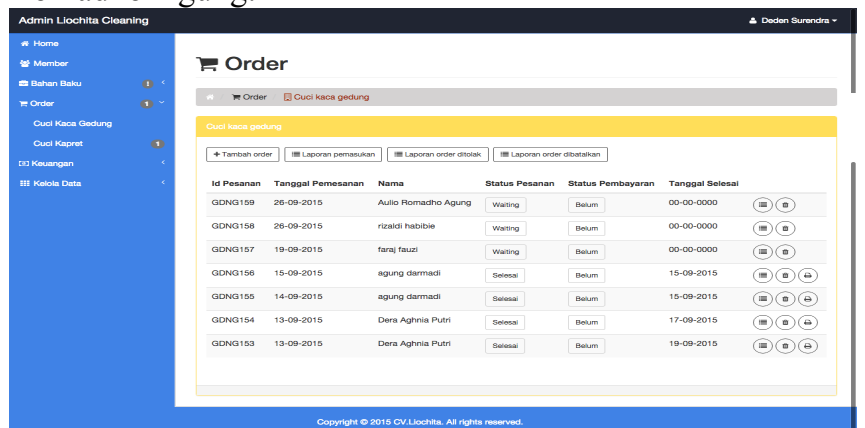

Gambar 12 Pengujian integrasi melihat pesanan cuci karpet

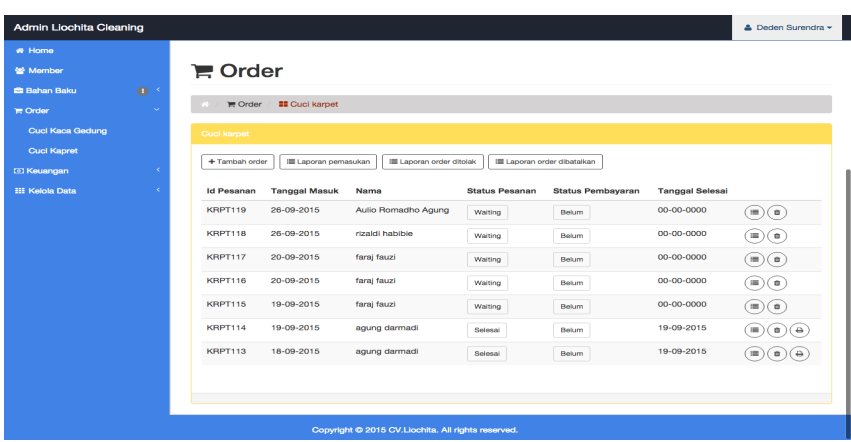

Gambar 13 Pengujian integrasi melihat pesanan cuci kaca gedung

Setelah admin melihat pesanan yang masuk, admin mengubah status pesanan. Status pesananakan ditampilkan pada pengguna pelanggan untuk mengetahui status pesanan yang telah dipesan. Gambar 14 menunjukkan mengubah status pesanan.

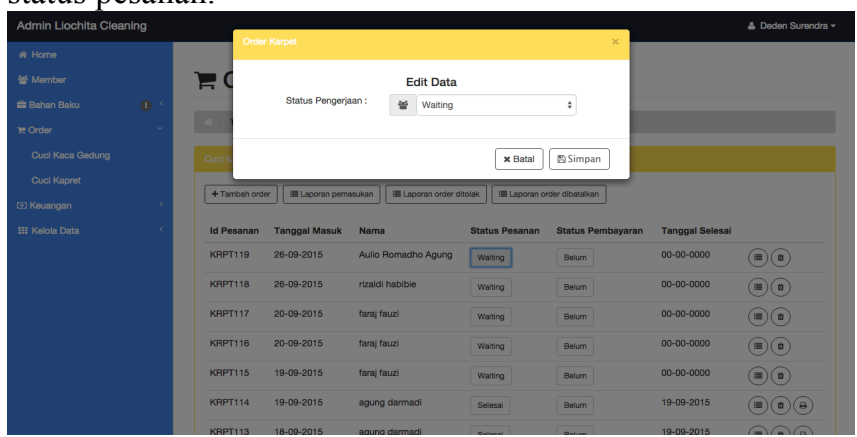

Gambar 14 Pengujian integrasi mengubah status pesanan

5. Pelanggan melihat status pesanan

Pelanggan yang telah melakukan pemesanan dapat melihat status pesanan, pelanggan dapat membayar kepada Liochita Cleaning apabila status pesanan telah selesai.Gambar 15 menunjukkan melihat status pesanan.

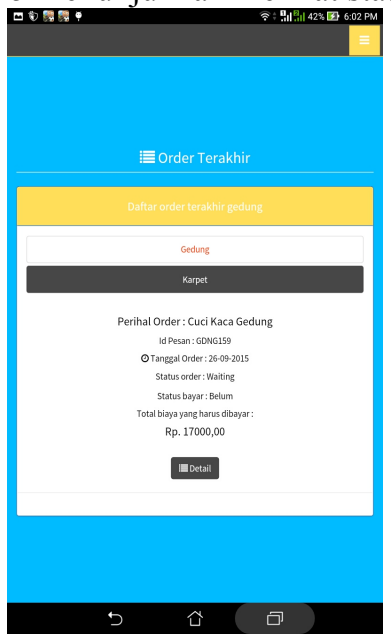

Gambar 15 Pengujian integrasi melihat status pesanan

6. Admin Liochita Cleaning mencetak nota

Admin dapat mencetak nota setelah status pesanan pelanggan yang telah selesai dikerjakan. Gambar 16 menunjukkan mencetak nota. 


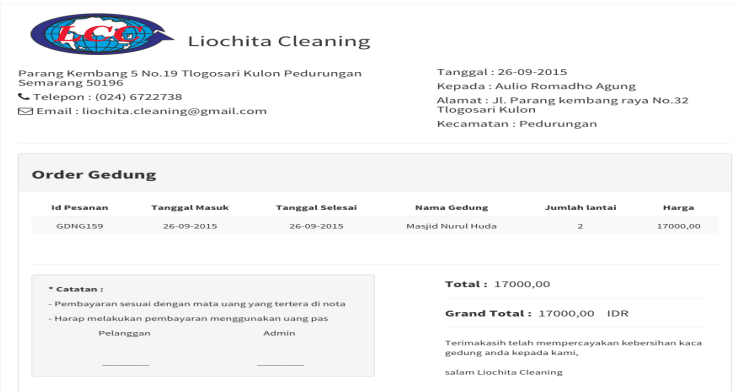

Gambar 16 Pengujian integrasi mengubah status pembayaran

7. Admin Liochita Cleaning melakukan perubahan status pembayaran

Admin dapat melakukan perubahan status pembayaran setelah pelanggan melakukan pembayaran. Gambar 17 menunjukkan mengubah status pembayaran.

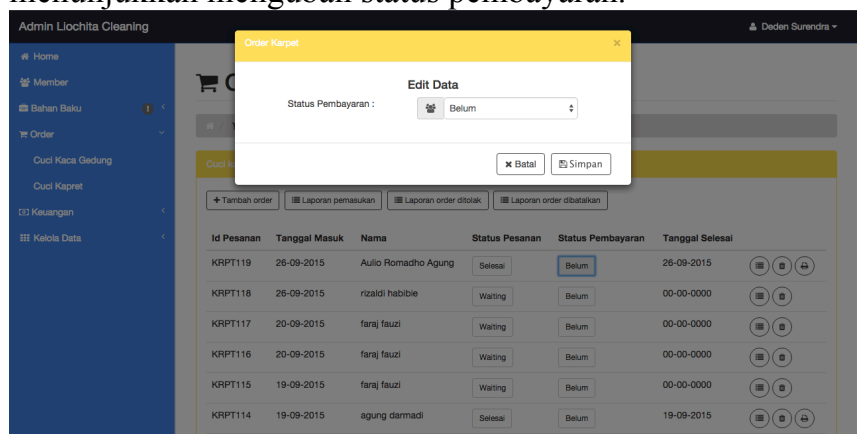

Gambar 17 Pengujian integrasi mengubah status pembayaran

8. Pelanggan melihat riwayat pemesanan

Pesanan yang telah dilakukan dapat dilihat riwayatnya oleh pelanggan melalui menu histori pesanan pada menu profil. Gambar 18 menunjukkan riwayat pesanan.

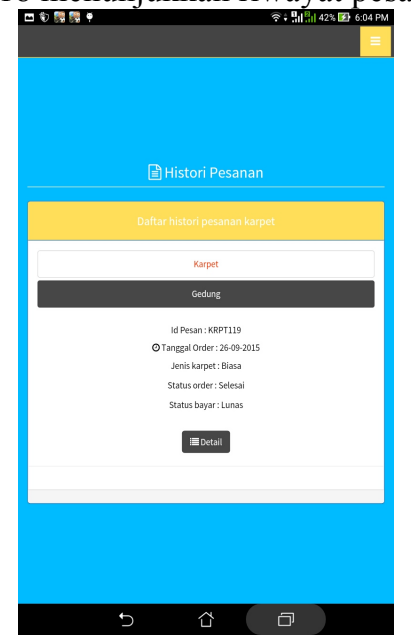

Gambar 18 Pengujian integrasi membaca riwayat pemesanan

9. Laporan

Transaksi yang dilakukan oleh pelanggan dan Admin Liochita Cleaning tercatat dalam sistem. Laporan dapat dilihat per tahun. Laporan pada tahun 2015dapat dilihat pada Gambar 19.

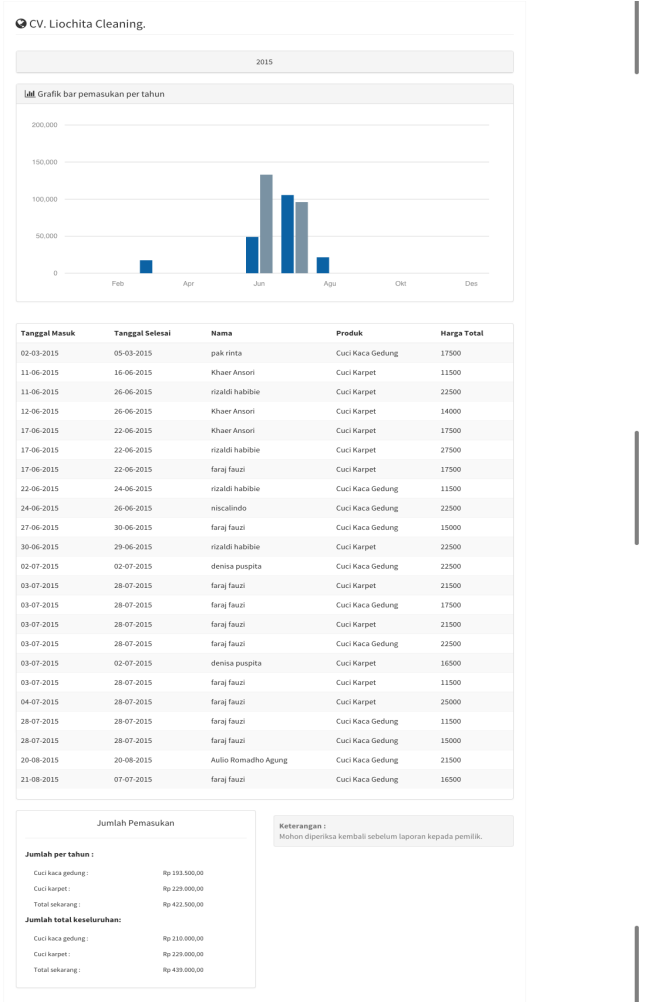

Gambar 19 Pengujian integrasi membaca laporan

Delapan skenario yang dijalankan menjelaskan bahwa sistem dapat mengintegrasikan unit dalam sistem untuk melakukan pekerjaan. Skenario yang diuji ditampilkan detail dengan fungsi terkait pada tabel 3.

Tabel 3 Hasil skenario pengujian integrasi

\begin{tabular}{|c|c|c|}
\hline Skenario & Fungsi Terkait & Analisis \\
\hline $\begin{array}{l}\text { Liochita } \\
\text { Cleaning } \\
\text { memiliki } \\
\text { beberapa data } \\
\text { cuci karpet dan } \\
\text { cuci kaca } \\
\text { gedung }\end{array}$ & $\begin{array}{l}\text { Login, membuat data cuci } \\
\text { karpet dan ckaca gedung, } \\
\text { membuat data supplier, } \\
\text { membuat data nonsupplier, } \\
\text { membuat data wilayah dan } \\
\text { ongkos kirim, membuat data } \\
\text { beli bahan nonsupplier, } \\
\text { membuat data beli bahan } \\
\text { supplier, membuat data beli } \\
\text { bahan supplier, membuat data } \\
\text { bahan keluar, membuat data } \\
\text { pesanan cuci karpet, membuat } \\
\text { data pesanan cuci kaca guding }\end{array}$ & Berhasil \\
\hline $\begin{array}{l}\text { Pelanggan } \\
\text { mendaftar }\end{array}$ & Membuat data pelanggan & Berhasil \\
\hline $\begin{array}{l}\text { Pelanggan } \\
\text { melakukan } \\
\text { pemsanan } \\
\text { layanan jasa }\end{array}$ & $\begin{array}{l}\text { Login, melakukan pemesanan } \\
\text { layanan jasa cuci kaca gedung } \\
\text { atau cuci karpet }\end{array}$ & Berhasil \\
\hline $\begin{array}{l}\text { Admin } \\
\text { mengelola } \\
\text { pesanan yang } \\
\text { telah dilakukan } \\
\text { oleh pelanggan }\end{array}$ & $\begin{array}{l}\text { Login, melihat status pesanan, } \\
\text { mengubah status pesanan, } \\
\text { mencetak nota }\end{array}$ & Berhasil \\
\hline $\begin{array}{l}\text { Pelanggan } \\
\text { melihat status } \\
\text { pesanan }\end{array}$ & Login, melihat status pesanan & Berhasil \\
\hline $\begin{array}{l}\text { Admin } \\
\text { Liochita } \\
\text { Cleaning } \\
\text { melakukan }\end{array}$ & $\begin{array}{l}\text { Login, mengubah status } \\
\text { pembayaran }\end{array}$ & Berhasil \\
\hline
\end{tabular}




\begin{tabular}{|l|l|l|}
\hline $\begin{array}{l}\text { perubahan } \\
\text { status } \\
\text { pembayaran }\end{array}$ & & \\
\hline $\begin{array}{l}\text { Pelanggan } \\
\text { melihat riwayat } \\
\text { pemesanan }\end{array}$ & Membaca riwayat pemesanan & Berhasil \\
\hline Laporan & Login, membaca data laporan & Berhasil \\
\hline
\end{tabular}

Tahap pengujian yang dilakukan menunjukkan sistem memiliki fungsi yang bekerja dengan benar.

\section{PENUTUP}

\section{A Kesimpulan}

Selama pengembangan sistem ini terdapat beberapa hal yang bisa disimpulkan. Kesimpulan yang didapatkan antara lain:

1. Sistem informasi dapat mengolah data pelanggan sesuai kebutuhan dengan lebih baik dibanding metode sebelumnya yang dalam pencatatan data pelanggan dan data pesanan masih menjadi satu yaitu data pemasukan sehingga perusahaan kurang mengetahui data pelanggan secara terperinci.

2. Sistem informasi dapat mengolah data riwayat pesanan sesuai kebutuhan dengan risiko data hilang atau rusak lebih kecil daripada metode sebelumnya yang dalam melakukan pencatatan semua data masih menggunakan kertas hal ini memiliki resiko kertas dan data yang telah tercatat tersebut hilang.

3. Sistem dapat digunakan oleh pengguna dengan mudah karena sistem dirancang untuk bekerja sesuai dengan bisnis proses yang ada sehingga mempermudah proses adaptasi.

4. Sistem yang dikembangkan dapat memfasilitasi kegiatan pemesanan jasa oleh pelanggan dan pelayanan oleh karyawan sesuai kebutuhan perusahaan Liochita Cleaning.

5. Sistem yang dikembangkan dapat menampilkan data pesanan per tahun untuk kemudian dibuat menjadi laporan pemasukan.

B Saran

1. Sistem informasi ini memiliki banyak aspek untuk dikembangkan seperti integrasi dengan sistem manajemen karyawan.

2. Fitur absensi karyawan dan gaji karyawan pada sistem manajemen karyawan belum bisa diimplementasikan karena dibutuhkan perancangan dan pengembangan sistem yang berbeda.

\section{DAFTAR PUSTAKA}

[1] Bell, C. (2012). Expert MySQL. Apress.

[2] Fauzan, Milady Reza. "Perancangan Sistem Pemesanan Produk Berbasis Web Pada CV. Hanif Niaga Group," 2008.

[3] Hidayat, Rakasiwi Syarief. "Perancangan Sistem Informasi Pelayanan Jasa Laundry Pada Hello Laundry," 2014.

[4] Jhon Burch, Gary Grudnitski. 1989. Information System Theory and Practice. New York: John Wiley \& Sons.

[5] M. Huda dan B. Komputer, Membuat Aplikasi Database Dengan Java, MySql dan NetBeans, Jakarta: Elex Media Komputindo, 2010.

[6] Spurlock Jack, Bootstrap Responsive Web Development, California: O'Reilly Media, Inc, 2013.
[7] Wardana. 2000. Menjadi Master PHP dengan Framework Codeigniter. Jakarta: PT Elex Media komputindo.

[8] Winina, Ardiana. "Sistem Informasi Pelayanan Salon Kecantikan Berbasis Web Dengan Menggunakan Framework Codeigniter," 2011. 